\title{
Penicillimide, an open-chain hemisuccinimide from Okinawan marine-derived Penicillium copticola
}

\author{
Ying-Yue Bu, Hiroyuki Yamazaki, Kazuyo Ukai and Michio Namikoshi \\ The Journal of Antibiotics (2015) 68, 537-539; doi:10.1038/ja.2015.21; published online 25 February 2015
}

Microbial products have contributed to human health care and the treatment of diseases. ${ }^{1}$ Fungi isolated from marine environments are a rich source of bioactive natural products as well as terrestrial isolates, and a large number of metabolites with unique structures and bioactivities have been reported from marine-derived fungi. ${ }^{1-4}$ During the course of an antifungal screening assay, we found that marinederived Penicillium copticola strain TPU1270 isolated from Iriomote Island in Okinawa, Japan, exhibited growth inhibitory activity against Mucor hiemalis IAM6088 (20 mm at $200 \mu \mathrm{g}$ per disc). Bioassay-guided isolation from the culture broth of strain TPU1270 yielded an openchain hemisuccinimide, named penicillimide (1), together with five known eremophilane sesquiterpenes: sporogen-AO 1 (2), ${ }^{5,6} 3$-acetyl13-deoxyphomenone (3), ${ }^{7,8}$ 6-dehydropetasol (4), ${ }^{9}$ 7-hydroxypetasol (5), ${ }^{9}$ and petasol (6) ${ }^{10}$ (Figure 1a). Compound $\mathbf{1}$ has been obtained by organic synthesis, and this is the first time to report this compound as a natural product. The isolation and antifungal activities of compounds 1-6 have been described herein.

The fungal strain TPU1270 was isolated from marine foam collected on the seashore in Iriomote Island, Okinawa Prefecture, Japan, in September 2012. Namely, $\sim 1 \mathrm{ml}$ of sterilized natural sea water was added to the marine foam collected in a sterilized plastic bag, the solution was mixed with $25 \mathrm{ml}$ of sterilized natural sea water with $1.0 \%$ SDS and $50 \mu \mathrm{l}$ of the resulting mixture was spread on an agar plate consisting of glycerol (Wako, Osaka, Japan) 0.6\%, arginine (Wako) $0.1 \%, \mathrm{~K}_{2} \mathrm{HPO}_{4}$ (Wako) $0.1 \%, \mathrm{MgSO}_{4}$ (Wako) $0.05 \%$, agar (Wako) 1.5\%, cycloheximide (Wako) $100 \mu \mathrm{g} \mathrm{ml}^{-1}$ and rifampin (Wako) $5 \mu \mathrm{g} \mathrm{ml}^{-1}$ in natural sea water. The fungus that grew on the plate was isolated and maintained on a potato dextrose (PD) agar plate (BD, Franklin Lakes, NJ, USA), and was identified as P. copticola by a comparison of 228 bp ITS1 ribosomal DNA sequences (100\% match). The mycelia that grew on the agar plate were inoculated into a $100-\mathrm{ml}$ Erlenmeyer flask containing $50 \mathrm{ml}$ of PD broth (BD), and the flask was shaken ( 150 r.p.m.) at $25^{\circ} \mathrm{C}$ for 3 days (seed culture). Aliquots $(2 \mathrm{ml})$ of the seed culture were inoculated into 15 Erlenmeyer flasks of $500 \mathrm{ml}$ with each containing $200 \mathrm{ml}$ of the main culture medium (sucrose (Wako) 3.0\%, soluble starch (Wako) 3.0\%, malt extract (BD) $1.0 \%$, Ebios (Asahi Food \& Healthcare, Tokyo, Japan) $0.3 \%, \mathrm{KH}_{2} \mathrm{PO}_{4} 0.5 \%$ and $\mathrm{MgSO}_{4} \cdot 7 \mathrm{H}_{2} \mathrm{O}$ (Wako) $0.05 \%$; adjusted to $\mathrm{pH} 6.0$ before sterilization), and the flasks were cultured statically at room temperature for 21 days.

Acetone (1.51) was added to the culture broth (31) and filtered. The filtrate was evaporated to remove acetone, and the aqueous residue was applied on an ODS column. The column was eluted stepwise with $\mathrm{H}_{2} \mathrm{O}-\mathrm{MeOH}$ (100:0 to 0:100) to afford 10 fractions. The $40 \% \mathrm{MeOH}$ fraction $(309.2 \mathrm{mg}$ ) was separated by preparative HPLC on an ODS column (Pegasil ODS SP100, $10 \mathrm{~mm} \times 250 \mathrm{~mm}$, Senshu Scientific, Tokyo, Japan) with $\mathrm{MeOH}-\mathrm{H}_{2} \mathrm{O}=44: 56\left(2.0 \mathrm{ml} \mathrm{min}^{-1}\right.$, UV $\left.210 \mathrm{~nm}\right)$ to give $30.0 \mathrm{mg}$ of $\mathbf{1}$ as solid. Preparative ODS HPLC (MeOH$\mathrm{H}_{2} \mathrm{O}=55: 45,2.0 \mathrm{ml} \mathrm{min}^{-1}$, UV $210 \mathrm{~nm}$ ) of the $50 \% \mathrm{MeOH}$ fraction (217.9 mg) afforded $15.0 \mathrm{mg}$ of 2 . Compound 3 (4.0 mg) was isolated from the $70 \% \mathrm{MeOH}$ fraction $(30.4 \mathrm{mg}$ ) by preparative HPLC (ODS, $\left.\mathrm{MeOH}-\mathrm{H}_{2} \mathrm{O}=75: 25\right)$, and $4(15.1 \mathrm{mg})$ and $\mathbf{6}(12.0 \mathrm{mg})$ were obtained from the $60 \% \mathrm{MeOH}$ fraction $(181.2 \mathrm{mg}$ ) by preparative ODS HPLC $\left(\mathrm{MeOH}-\mathrm{H}_{2} \mathrm{O}=66: 34\right)$. Preparative HPLC (ODS, $\mathrm{MeOH}-\mathrm{H}_{2} \mathrm{O}=$ 33:67) of the $30 \% \mathrm{MeOH}$ fraction (174.6 mg) yielded $5.5 \mathrm{mg}$ of 5 .

The structures of compounds 2-6 were identified by comparing their spectroscopic data with the reported values for sporogen-AO 1 (2), 3-acetyl-13-deoxyphomenone (3), 6-dehydropetasol (4), 7-hydroxypetasol (5) and petasol (6) ${ }^{6-12}$ (Figure 1a).

Compound 1 was obtained as pale yellow solid. The molecular formula of $1, \mathrm{C}_{13} \mathrm{H}_{14} \mathrm{NO}_{5} \mathrm{Cl}$, was deduced from high-resolution electron ionization mass spectrometry (HREIMS; m/z 299.0555 $(\mathrm{M})^{+}, \Delta-0.6 \mathrm{mmu}$ ) and NMR data. Compound 1 showed UV absorptions at $202 \mathrm{~nm}(\log \varepsilon$ 3.69) and $280 \mathrm{~nm}(\log \varepsilon$ 2.80). IR absorptions at $1635-1739$ and $3419 \mathrm{~cm}^{-1}$ suggested the presence of carbonyl and hydroxy groups in the molecule. The ${ }^{1} \mathrm{H}$ and ${ }^{13} \mathrm{C}$ NMR signals were assigned by analyzing ${ }^{1} \mathrm{H}_{-}{ }^{1} \mathrm{H}$ COSY, heteronuclear multiple quantum coherence (HMQC) and heteronuclear multiple bond correlation (HMBC) spectra (Table 1). The ${ }^{1} \mathrm{H}-{ }^{1} \mathrm{H}$ COSY spectrum of 1 revealed a 1,3,4-trisubstituted benzene ring (partial structure I) and partial structure II as shown by bold lines in Figure $1 \mathrm{~b}$. The ${ }^{13} \mathrm{C}$ NMR data of 1 showed the presence of three amide/ester carbonyl carbons at $\delta 173.8,174.9$ and 175.2. Partial structures I and II, three carbonyls and an OMe group were connected from the HMBC data (Figure $1 \mathrm{~b})$. NMR data measured in acetone- $d_{6}$ (Table 1) due to the 2-(3-chloro-4-hydroxyphenyl)acetylamide moiety 
<smiles>COC(=O)CCC(=O)NC(=O)Cc1ccc(O)c(Cl)c1</smiles><smiles>COC(=O)/C=C/C(=O)NC(=O)Cc1ccc(O)c(Cl)c1</smiles>

coniothyriomycin

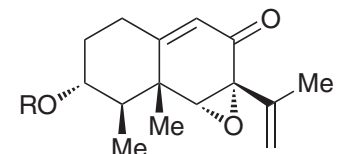

2: $\mathrm{R}=\mathrm{H}$

3: $R=A C$<smiles>C=C(C)C(=O)C1(O)CC2(O)C(=CC1=O)CC[C@@H](O)C2C</smiles>

5

b

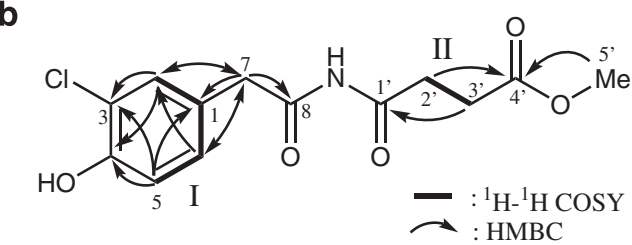

Figure 1 (a) Structures of compounds $1-6$ isolated from Penicillium copticola TPU1270 and coniothyriomycin. (b) ${ }^{1} \mathrm{H}^{1}{ }^{1} \mathrm{H}$ COSY and heteronuclear multiple bond correlation (HMBC) correlations for compound 1 .

in 1 were very similar to those of the same moiety in coniothyriomycin, previously identified as an antifungal metabolite from the fungus Coniothryrium sp. ${ }^{13}$ A difference in the structures of compound $\mathbf{1}$ and coniothyriomycin was detected at the dicarboxylic acid units (Figure 1a). Compound $\mathbf{1}$ had the succinic acid unit, whereas coniothyriomycin had the fumaric acid unit $\left(\Delta^{2^{\prime}}\right.$-succnic acid unit). Thus, the structure of compound $\mathbf{1}$ was assigned as shown in Figure 1. Compound $\mathbf{1}$ was found in the SciFinder as a commercially available reagent for drug discovery, and therefore this study is the first to report compound 1 as a fungal fermentation product. Compound 1 might be named as dihydro-coniothyrionmycin, but a suffix 'mycin' will not be suitable as compound $\mathbf{1}$ was a fungal metabolite. Accordingly, compound $\mathbf{1}$ was named as penicillimide.

The antifungal activities of compounds 1-6 were evaluated against M. hiemalis IAM 6088 and Aspergillus fumigatus IAM 13869 using the paper disc method (Supplementary Table S1). The culture broth of strain TPU1270 inhibited the growth of M. hiemalis, and this activity was reproduced by compounds $\mathbf{2 - 4}$ and $\mathbf{6}$. Compounds $\mathbf{2 ,} \mathbf{4}$ and $\mathbf{6}$ displayed inhibition zones of 7, 11 and $8 \mathrm{~mm}$, respectively, at $40 \mu \mathrm{g}$ per disc, whereas compound 3 showed modest activity $(9 \mathrm{~mm}$ at $80 \mu \mathrm{g}$ per disc). These compounds also inhibited the growth of $A$. fumigatus. Penicillimide (1) and compound $\mathbf{5}$ were not active against either test fungi at $80 \mu \mathrm{g}$ per disc. Amphotericin B, a positive control, showed
Table $1{ }^{13} \mathrm{C}(100 \mathrm{MHz})$ and ${ }^{1} \mathrm{H}(400 \mathrm{MHz}) \mathrm{NMR}$ data for compound 1 in $\mathrm{CD}_{3} \mathrm{OD}$ and acetone- $d_{6}$

\begin{tabular}{|c|c|c|c|c|c|}
\hline$C$ & $\delta_{C}{ }^{a}$ & $\delta_{H}$, mult. $(\mathrm{J} \text { in } H z)^{a}$ & $H M B C^{a}$ & $\delta_{C}^{\mathrm{b}}$ & $\delta_{H}$, mult. $(\mathrm{J} \text { in } \mathrm{Hz})^{\mathrm{b}}$ \\
\hline 1 & 127.9 & & & 128.3 & \\
\hline 2 & 132.1 & $7.22, \mathrm{~d}(2.1)$ & $3,4,6,7$ & 132.1 & $7.31, \mathrm{~d}(2.2)$ \\
\hline 3 & 121.7 & & & 121.1 & \\
\hline 4 & 153.6 & & & 153.1 & \\
\hline $4-\mathrm{OH}$ & - & & & - & $8.67, \mathrm{~s}$ \\
\hline 5 & 117.8 & $6.86, \mathrm{~d}(8.3)$ & $1,3,4,6$ & 117.7 & $6.95, \mathrm{~d}(8.3)$ \\
\hline 6 & 130.3 & 7.03, dd $(2.1,8.3)$ & $2,4,7$ & 130.4 & $7.10, \mathrm{dd}(2.2,8.3)$ \\
\hline 7 & 43.3 & $3.67, \mathrm{~s}$ & $1,2,6,8$ & 43.1 & $3.81, \mathrm{~s}$ \\
\hline 8 & 173.8 & & & 172.4 & \\
\hline 8-NH & - & & & - & $9.78, \mathrm{~s}$ \\
\hline $1^{\prime}$ & 174.9 & & & 173.7 & \\
\hline $2^{\prime}$ & 33.1 & $2.84, \mathrm{dd}(5.7,7.2)$ & $1^{\prime}, 3^{\prime}, 4^{\prime}$ & 33.1 & 2.94, dd $(6.5,6.5)$ \\
\hline $3^{\prime}$ & 29.1 & $2.61, \mathrm{dd}(5.7,7.2)$ & $1^{\prime}, 2^{\prime}, 4^{\prime}$ & 28.8 & 2.61 , dd $(6.5,6.5)$ \\
\hline $4^{\prime}$ & 175.2 & & & 174.1 & \\
\hline $5^{\prime \prime}$ & 52.4 & $3.66, \mathrm{~s}$ & $4^{\prime}$ & 52.0 & $3.61, \mathrm{~s}$ \\
\hline
\end{tabular}

Abbreviation: $\mathrm{HMBC}$, heteronuclear multiple bond correlation.

aNMR spectra were measured in $\mathrm{CD}_{3} \mathrm{OD}$.

bNMR spectra were measured in acetone- $d_{6}$.

inhibition zones of 12 and $13 \mathrm{~mm}$ at $10 \mu \mathrm{g}$ per disc against $M$. hiemalis and A. fumigatus, respectively.

Although penicillimide (1) did not exhibit antifungal activity, coniothyriomycin $\left(\Delta^{2^{\prime}}\right.$-analog of $\left.\mathbf{1}\right)$ was previously shown to be active against several fungal strains. ${ }^{13,14}$ Therefore, a double bond at the side chain will be necessary for the antifungal activities of these imides. ${ }^{14}$

\section{ACKNOWLEDGEMENTS}

This work was supported in part by a Grant-in-Aid for Scientific Research (25870660) from the Ministry of Education, Culture, Sports, Science and Technology (MEXT) of Japan to HY and by the Foundation for Japanese Chemical Research to HY. We thank Mr T Matsuki and S Sato of Tohoku Pharmaceutical University for measuring mass spectra.

1 Demain, A. L. \& Sanchez, S. Microbial drug discovery: 80 years of progress. J. Antibiot. 62, 5-116 (2009).

2 Blunt, J. W., Copp, B. R., Keyzers, R. A., Munro, M. H. \& Prinsep, M. R. Marine natural products. Nat. Prod. Rep. 31, 160-258 (2014) and previous reports in this series.

3 Bhatnagar, I. \& Kim, S. K. Immense essence of excellence: marine microbial bioactive compounds. Mar. Drugs 8, 2673-2701 (2010).

4 Swathi, J., Narendra, K., Sowjanya, K. M. \& Satya, A. K. Marine fungal metabolites as a rich source of bioactive compounds. Afr. J. Biochem. Res. 7 , 184-196 (2013)

5 Tirilly, Y., Kloosterman, J., Sipma, G. \& Bosch, J. J. K.-V. D. A fungitoxic sesquiterpene from Hansfordia pulvinada. Phytochemistry 22, 2082-2083 (1983).

6 Tanaka, S., Wada, K., Marumo, S. \& Hattori, H. Structure of sporogen-AO 1, a sporogenic substance of Aspergillus oryzae. Tetrahedron Lett. 25 5907-5910 (1984).

7 Schneider, G., Anke, H. \& Sterner, O. New secondary metabolites from a mycophilic Hansfordia species. Nat. Prod. Lett. 10, 133-138 (1997).

8 Huang, Y. F., Qiao, L., Lv, A. L., Pei, Y. H. \& Tian, L. Eremophilane sesquiterpenes from the marine fungus Penicillium sp. BL27-2. Chinese Chem. Lett. 19, 562-564 (2008)

9 Sugawara, F. et al. Phytoactive eremophilanes produced by the weed pathogen Drechslera gigantea. Biosci. Biotech. Biochem. 57, 236-239 (1993).

10 Sugama, K., Hayashi, K., Nakagawa, T., Mitsuhashi, H. \& Yoshida, N. Sesquiterpenoids from Petasites fragrans. Phytochemistry 22, 1619-1622 (1983).

11 Le, D. H., Takenaka, Y., Hamada, N. \& Tanahashi, T. Eremophilane-type sesquiterpenes from cultured lichen mycobionts of Sarcographa tricosa. Phytochemistry 91 242-248 (2013)

12 Yurchenko, A. N. et al. Biologically active metabolites of the facultative marine fungus Penicillium citrinum. Chem. Nat. Comp. 48, 996-998 (2013).

13 Krohn, K. et al. Isolierung, Synthese und biologische Wirkung von Coniothyriomycin sowie Synthese und Biotestung analoger offenkettiger Imide (Biologically active 
metabolites of fungi, I. - Isolation, synthesis, and biological activity of coniothyriomycin as well as bioassay of analogous open-chain imides). Liebigs Ann. Chem. 8, 789-798 (1992).
14 Krohn, K., Elsässer, B., Antus, S., Kónya, K. \& Ammermann, E. Synthesis and structure-activity relationship of antifungal coniothyriomycin analogues. J. Antibiot. 56, 296-305 (2003)

Supplementary Information accompanies the paper on The Journal of Antibiotics website (http://www.nature.com/ja) 